\title{
VISÃO ATUALIZADA DA VIOLÊNCIA DOMÉSTICA NO BRASIL E O VERDADEIRO ALCANCE DA LEI MARIA DA PENHA - LEI No 11.340/2006
}

\author{
Luciana Flávia de Oliveira Moreira \\ Concludente do curso de Especialização em Direito Processual \\ (FA7), orientada pelo prof. Ms. Felipe dos Reis Barroso (FA7). \\ Advogada. \\ lucianamoreiradv@hotmail.com
}

Sumário: Introdução. 1. Violência Doméstica Contra a Mulher. 2. Lei Maria da Penha. 3. Análise do Panorama Social e Finalidade Atual. 4. Índices Atualizados sobre a Violência Doméstica no Brasil. Conclusão. Referências.

Resumo: O presente artigo tem como finalidade a evolução e o reconhecimento dos direitos das mulheres vítimas de violência doméstica. Pretende-se com o tema abordar importantes questões, que vão desde a origem dos primeiros movimentos feministas em nosso país, suas aguerridas lutas e constantes embates, passando por conceitos e classificações literais de violência, seus tipos, o ambiente propício à sua ocorrência, bem como a análise da lei propriamente dita, aplicabilidade, o real funcionamento das Delegacias, Centros de apoio e Juizados Especiais criados especificamente para atender esse público-alvo, há muito necessitado de amparo legal. Somando-se a isso, o desafio maior é saber se esse diploma, tão bem intencionado, pelo menos em sua origem, vem realmente atendendo aos fins para os quais foi criado, se pode, ou se está sendo utilizado por muitas mulheres apenas como mero instrumento de vingança contra seus namorados, esposos ou ex-esposos, companheiros etc. Trata-se de um tema de relevante valor social, cultural, por sua atualidade, podendo servir de termômetro para o próprio Poder Judiciário.

Palavras-chave: Violência Doméstica. Combate. Lei Maria da Penha. Delegacia de Defesa da Mulher. Juizados Especiais. Eficácia.

\section{INTRODUÇÃO}

Ao longo dos tempos, a espécie humana vem passando por diversas etapas evolutivas, mas sempre mantendo a diferença entre seus gêneros: homem e mulher. Tal diferença acaba gerando conflitos, que, por sua vez, mal resolvidos ou não resolvidas geram violência, afetando, inclusive, as possibilidades de crescimento social e, principalmente, econômico, uma vez que mulheres vítimas de violência doméstica ganham menos do que aquelas que não a vivenciam, em tese, pois são vistas como seres inferiores, sendo obrigadas à submissão a todos os tipos de vontades.

Tal opressão gera desgastes de ordens físicas e psicológicas nessas mulheres, causando-lhes sérios prejuízos emocionais, biológicos e afetivos, fazendo emergir a necessidade de mecanismos efetivos que as resgatem deste estágio de desigualdade e as concedam a igualdade de direitos de gêneros, o respeito e sua inclusão num mundo com predominância de pensamento e de comportamentos machistas. 
Diversos são os meios utilizados como forma de agressão com vistas a reprimir e/ou violentar essas mulheres, tais como: a violência moral, psicológica, sexual, física e até mesmo patrimonial.

Diante do crescimento assustador de tais condutas, formas veladas de preconceito, racismo e desigualdade praticadas ao longo de gerações, uma vez que não existia nenhum mecanismo que amparasse de forma expressa a mulher vítima de violência, e, após o surgimento de uma conscientização, oriunda do cansaço e repressão a que eram submetidas, eis que, no dia 07 de agosto de 2006, foi sancionada a Lei n 11.340, intitulada de "Maria da Penha" em alusão a uma mulher cearense, símbolo de resistência e luta, diga-se um milagre de vida, que transformou sua dor em bálsamo e possibilidade de mudança de vida, amparo social e legal e de verdadeira arma de proibição de condutas ilícitas tão graves, atentatórias aos Direitos Fundamentais e Individuais basilares de nosso Diploma Legal.

\section{VIOLÊNCIA DOMÉSTICA}

\subsection{Aspectos da Violência no Brasil}

A América Latina é uma das regiões detentoras dos maiores índices de violência doméstica no mundo, em casa ou nas ruas. As taxas de homicídio correspondem a mais que o dobro da média mundial, e quase metade das mulheres sofrem maus tratos psicológicos, enquanto duas em cinco, sofrem violência física. (MORRISON; BLEHL, 2000)

No Brasil, o movimento contra a violência doméstica emergiu, em parte, no período da ditadura militar, precisamente na década de 1970, onde houve, no final desta, uma liberalização gradual que culminou com a eleição indireta para escolha de um presidente civil em 1985, iniciando-se assim, o surgimento de uma democracia que tinha como sistema de governo o Presidencialismo tendo como consequência direta a promulgação da Constituição da República Federativa do Brasil no ano 1988, que trazia em seu escopo os Direitos e Garantias Fundamentais, Individuais e Coletivas, orientadoras do dever ser.

A partir de então, vieram à tona e ao conhecimento da sociedade inúmeros relatórios sobre abuso sexual, torturas ocorridas durante o período regido pelos militares, que provocaram inúmeros debates nacionais sobre o tema violência.

Ressalte-se que, ainda na década de 1970, surgiram várias organizações não governamentais de defesa dos direitos humanos com a participação pequena, mas ativa, de algumas destemidas mulheres. Com o crescimento do movimento pró-democracia, o debate sobre o tema intensificou-se, surgindo, com isso, diversos grupos de mulheres dispostas a darem força e voz e ao movimento, sendo o mais famoso deles o "SOS MULHER", organização nacional dedicada exclusivamente ao combate à violência contra a mulher. Concorreram também nesta época para uma maior explosão dessas campanhas e movimentos, o acontecimento de dois casos envolvendo pessoas famosas, conhecidas em âmbito nacional, um no Estado do Rio de Janeiro e outro em São Paulo, casos estes que serviram de mola propulsora para os movimentos de mulheres no Brasil, onde naceu a frase de autor desconhecido que tornou-se o slogan principal dessas campanhas "QUEM AMA NÃO MATA”.

Nos Estados de São Paulo e Minas Gerais, foram criados os primeiros conselhos da condição feminina, mas especificamente em São Paulo. Esse conselhos tinham por objetivo básico a ampliação ao acesso das mulheres ao processo de participação nas decisões políticas e de promoção dos interesses femininos na administração estadual. 
Entre os anos de 1982 e 1985, tanto durante a campanha para a eleição de Tancredo Neves, quanto durante os primeiros meses no exercício da presidência por José Sarney (após a morte daquele), um grupo de mulheres propuseram a criação de um Órgão Federal, voltado para o efetivo desenvolvimento de políticas públicas, apresentando propostas de mudanças na legislação, bem como a prestação de assessoria ao Presidente da República e aos Órgãos da Administração Federal concernentes às questões relativas à melhoria da condição da mulher brasileira.

Como consequência dos esforços desses grupos, em agosto de 1985, através de Lei Federal, foi instituído o Conselho Nacional dos Direitos da Mulher (CNDM), tendo como finalidade precípua, notadamente, o combate à violência contra as mulheres, colocando como prioritária a questão da violência específica de gênero, lançando, na ocasião, a campanha "DIGA NÃO À VIOLÊNCIA CONTRA A MULHER".

A partir daí, as mulheres passaram a ter uma maior representatividade junto às esferas política e profissional, com uma maior abertura para seu ingresso no mercado de trabalho, onde pesquisas realizadas, à época, davam conta de que a "população feminina economicamente ativa" subiu de $18,5 \%$ em 1970, para 26,9\% em 1980, correspondendo a um aumento de $41 \%$ do total da população economicamente ativa da década.

O tipo de ocupação feminina também mudou, posto que a taxa da população feminina economicamente ativa em cargos administrativos aumentou de 9,2\%, em 1960; para 15,4\%, em 1980; e de 19.000, em 1970, para 95.800, em 1980, nas profissões de maior prestígio, tais como: engenharia, medicina, odontologia, economia, ensino universitário e advocacia. Ainda nesse ano (1980), o número de mulheres matriculadas nas universidades brasileiras era quase igual ao número de homens.

O aumento do poder econômico e político das mulheres, aliado ao desenvolvimento de organismos femininos oficiais, ou não, de certa forma serviram de instrumento para pressionar e sensibilizar o governo e a sociedade na luta por mudanças básicas na forma com que tratavam as questões ligadas à violência específica de gênero.

Posteriormente, alguns grupos organizados de defesa dos direitos das mulheres, em parceria com o Conselho Estadual da Condição Feminina do Estado de São Paulo, persuadiram o governado da época (um oposicionista) a criar uma delegacia composta por policiais do sexo feminino para lidar exclusivamente com os crimes violentos praticados contra a mulher, exceto os de homicídio, o qual não era tido como um crime específico de gênero. Como prova ou sinal de força, ao final desse mesmo ano, já havia no Estado de São Paulo oito delegacias de defesa da mulher. Surgindo assim, as primeiras DDM's do Brasil, oficialmente. Em 1990, totalizavam 74 unidades que hoje, já somam mais de 397 nos Estados mais o Distrito Federal, segundo estimativa de estudo realizado pela rede de serviços de atenção às mulheres, do ano 2007, em todo o País, como será posteriormente demonstrado em seu funcionamento. (DOXSEY, 2001)

A Constituição Federal, em seu art. 226, parágrafo $8^{\circ}$, reflete muito as exigências do movimento nacional de mulheres estabelecendo que "O Estado assegurará a assistência à família na pessoa de cada um dos membros que a integram, criando mecanismos para coibir a violência no âmbito de suas relações". Tal dispositivo fora aditado em Constituições Estaduais em todo o país.

Indubitavelmente, as conquistas dos movimentos femininos e/ou feministas no Brasil na reinvidicação de respostas contundentes e assecuratórias de direitos por parte do Estado contra a violência doméstica, são inquestionáveis e impressionam, pois ao longo dos anos, o movimento nasceu, ganhou voz e força política, criou organismos públicos com vistas a intensificar o combate oficial, atingindo seu ápice com o advento da Lei Maria da Penha (Lei n 11.340/2006) que hoje regula esse tipo de conduta ilícita, covarde e moralmente reprovável, com diretrizes exatas quanto 
aos objetivos e fins a que se destina. Representando de forma valorosa um magnífico avanço, ante uma legislação machista, protecionista, que esbarrava em punições vis, de aspecto humilhante e vexatório com míseros pagamentos de cestas básicas, prestações de serviços à comunidade ou condenações por motivo de violenta condenação após injusta provocação da vítima, que, muitas vezes pagava com a própria vida.

Segundo a Conferência Mundial das Nações Unidas sobre a Mulher: a expressão "Violência contra a mulher" foi definida oficialmente na declaração (art $1^{\circ}$ ) bem como na plataforma de Ação Beijing (parágrafo 113) como sendo "Todo ato de violência baseado na pessoa pertencente ao sexo feminino que tenha ou possa ter como resultado um dano ou sofrimento físico, sexual, psicológico para a mulher, assim como as ameaças de tais atos, a coação ou privação arbitrária de liberdade, tanto se são produzidos na vida pública como na vida privada”.

A convenção internacional para prevenir, punir e erradicar a violência contra a mulher, ocorrida na cidade de Belém, no Estado do Pará, e, adotada pela OEA (Organização dos Estados Americanos) em 1994, definiu violência contra as mulheres, após Resolução da Assembléia Geral das Nações Unidas como "uma manifestação de relações de poder historicamente desiguais entre homens e mulheres que conduzem à discriminação contra as mulheres pelos homens e impedem o pleno avanço das mulheres".

Sendo assim, pode-se dizer que a violência doméstica corresponde a todo o ato de agressão, ação ou omissão contra a mulher, realizada por pessoas que possuem ou não vínculo familiar, podendo ser provisoriamente agregadas dentro de um ambiente, sendo este doméstico, íntimo ou até mesmo familiar.

Alguns índices sobre a violência impressionam pela perversidade. Segundo dados da Organização Mundial de Saúde, OMS, 30\% das mulheres foram forçadas em suas primeiras relações sexuais; $52 \%$ são alvo de assédio sexual; $69 \%$ já foram agredidas ou violadas. Isso tudo, sem contar o número de homicídios praticados por marido e companheiros sempre sobre a pífia alegativa de defesa da honra. (DIAS, 2008)

\subsection{Classificação de Violência}

São formas de violência doméstica e familiar contra a mulher, entre outras:

I - Violência Física: compreendida como qualquer conduta que ofenda sua integridade ou saúde corporal, qualquer lesão corporal ou dor a outra pessoa. Os agressores podem infligir esta lesão com seus próprios corpos ou com algum outro objeto. Empurrões, puxões de cabelo, beliscões, apertos, torceduras, bofetadas, socos, chutes, pancadas com objetos, batidas contra a parede, queimaduras ou ataques com objetos contundentes ou pérfurocortantes, e mais comumente, armas de fogo. (ALMEIDA, 2010, online)

II - Violência Sexual ou Coerção: definida como qualquer ato no qual uma pessoa que se encontra em posição de poder, exija que a outra pessoa pratique atividades sexuais contra a sua vontade, por meio de ameaças, chantagem ou emprego de força física, abrangendo ainda a submissão de alguém à exibição de órgãos sexuais, tocar, acariciar outrem contra sua vontade, forçá-la a assistir a material de cunho pornográfico, exigir que alguém lhe toque a genitália, ou forçá-la a manter contato sexual com uma terceira pessoa ou expô-la intencionalmente a doenças sexualmente transmissíveis. (ELUF, 1999)

III - Violência Psicológica: constitui-se basicamente de condutas omissivas ou comissivas que geram danos ao equilíbrio emocional e psicológico da mulher, sendo tão grave ou mais que a violência física. Nela, o agente agressor tem o prazer de inferiorizar a 
vítima, utilizando-se do medo, passando a amedrontar, ameaçar, rejeitar, discriminar, insultar, fazendo chantagem e ironias, perseguindo-a, isolando-a, privando-a de sua liberdade, etc. Tal ação resulta num desequilíbrio psicoemocional, levando à degeneração da mulher vitimada, diminuindo cada vez mais sua capacidade de reação e resistência, interferindo em sua própria identidade, acarretando um grave prejuízo mental que virá futuramente causar-lhe problemas físicos. A mulher que sofre esse tipo de violência passa a apresentar autoestima baixa, devido às diversas privações a qual é submetida, ficando desprovida de autodeterminação, identidade própria, apresentando cada vez menos resistência e coragem para buscar ajuda, vivendo de intenso medo e caindo dentro do mundo em que o seu repressor deseja colocá-la. (ALMEIDA, 2010, online)

Dessa forma, a vítima deixa de lado sua própria vida, suas opiniões, vontades, projetos traçados, apresentando um quadro de depressão progressiva, vivendo apenas uma ilusão que lhe é apresentada e na qual é obrigada a seguir sob pena de maus tratos e até mesmo de morte; Acabando por aceitar tal condição de violência para proteger até mesmo os filhos, também usados pelo seu opressor como forma de tormento psicológico.

IV - Violência Patrimonial: caracteriza-se por todo e qualquer ato que implique em retenção, subtração, destruição parcial ou total de bens, documentos, valores, direito e recursos econômicos sobre os quais a vítima possua titularidade. Trata-se de uma espécie de violência que normalmente vem acompanhada de outras mais, pois acaba sendo usada para causar danos psicológicos e físicos à mulher tida como vítima. Os bens subtraídos ou danificados não precisam necessariamente ser de ordem econômica, mas também podem apresentar valor pessoal e sentimental (afetivo), assim como aqueles que são necessários para o exercício de atividade civil ou profissional. Sendo assim, qualquer ato (queimar, amassar, rasgar, esconder...) que destrua ou agrida esses valores são caracterizados como espécie de violência patrimonial. Geralmente tal violência é praticada com o objetivo de impedir que a mulher deixe uma relação da qual a mesma pretende se retirar, como forma de coação e vingança. (HERMANN, 2007)

V - Violência Moral: tal espécie pode ser claramente confundida com a violência psicológica, porém a violência moral ocorre sempre que for imputada à mulher vitimada uma Calúnia (falsa imputação de crime), Difamação (falsa atribuição de condutas desonrosas e vergonhosas perante terceiros) ou Injuria (ofensa ou insulto proferido contra a vítima), figuras estas que se encontram tipificadas nos artigos $\mathrm{n}^{\circ} 138,139$ e 140 do Código Penal Brasileiro. (ALMEIDA, 2010, online)

\section{Lei Maria da Penha - Lei n ${ }^{0}$ 11.340/2006}

A lei em comento foi criada e intitulada em homenagem a uma Cearense, de nome Maria da Penha Maia Fernandes, formada no curso de farmácia pela Universidade Federal do Ceará - UFC, que, no dia 29 de maio de 1983, na Cidade de Fortaleza, sofreu uma tentativa brutal de homicídio praticada por seu próprio esposo, Sr. Antônio Heredia Viveiros, de origem Colombiana e naturalizado brasileiro, sendo atingida por um tiro de espingarda enquanto dormia. (CUNHA, 2007) Tal disparo atingiu e lesionou de forma irreversível a coluna de Maria da Penha, deixando-a paraplégica.

Após isso, e em razão da relação tumultuada, com ameaça estendida também às filhas do casal, não satisfeito, Antônio, homem de temperamento violento, marcado por um passado obscuro, acrescido de várias práticas delituosas, uma semana após disparo contra sua 
esposa, forjou outra agressão contra a mesma: enquanto se banhava, Maria da penha recebeu uma descarga elétrica.

Temendo outras agressões contra si e suas filhas, Maria da Penha resistia em denunciá-lo, visando uma possível separação amigável. Comovidos com a situação da vitima e de suas filhas, os empregados do casal denunciaram e depuseram contra o patrão agressor e propiciaram, com isso, o embasamento do inquérito policial e, posteriormente, o oferecimento da denúncia pelo Ministério Público perante a $1^{\text {a }}$. Vara Criminal de Fortaleza.

No dia 31 de outubro de 1986, o réu foi pronunciado e levado a júri, sendo em 4 de maio de 1991, condenado. Após acolhimento do recurso com pedido de realização de novo julgamento, o marido de Maria da Penha foi condenado à pena de 10 anos e 6 meses de prisão, porém, apenas 19 anos depois da prática do crime, o réu finalmente foi preso.

Diante do trágico caminho percorrido por Maria da Penha, foram tomadas medidas emergenciais para a criação e sanção da Lei de combate à violência contra a mulher, com a criação de um grupo de trabalho interministerial, formado pela Secretaria Especial de Políticas para a Mulher (SPM) da Presidência da República, Órgão este responsável pela coordenação dos trabalhos, em parceria com a Casa Civil da Presidência da República, a Advocacia Geral da União, o Ministério da Saúde, a Secretaria Especial dos Direitos Humanos da Presidência da República, a Secretaria Especial de Políticas de Promoção da Igualdade Racial da Presidência da República, o Ministério da Justiça e a Secretaria Nacional de Segurança Pública. Sendo encaminhado o Projeto de lei $\mathrm{n}^{\circ}$ 4.559/2004, elaborado pela SPM ao Congresso Nacional, pelo Presidente da Republica, no dia 03 de dezembro de 2004. (UNBEAUM, 2005, online)

No Congresso, o Projeto de Lei passou por diversas inovações e pedidos para que apresentasse definições do que viria a ser violência doméstica e familiar em todas as suas espécies. Havendo ainda inúmeras alterações no que diz respeito ao atendimento pela autoridade policial e equipes formadas por médicos, assistentes sociais, psicólogos que dão amparo às vítimas, do Ministério Público, bem como a ampliação de medidas cautelares que poderiam ser tomadas em relação ao agressor como forma de maior garantia de proteção às vitimas, apresentando para tanto, efeitos civis e penais.

Nesse mesmo passo, surgiu também a abolição do TCO, previsto na Lei n ${ }^{\circ} 9.099 / 95$, (Juizados Especiais), fazendo com que os fatos chegassem à autoridade policial da forma mais clara possível, como uma tentativa de resgate do inquérito policial previsto no Código de Processo Penal, além da possibilidade de prisão preventiva, excluindo-se a vedação da prisão em flagrante em prol dos crimes de violência doméstica e familiar praticados contra a mulher.

Sem dúvida, uma das mais importantes inovações propostas foi a introdução de realização de audiência de apresentação, onde a vítima seria ouvida pelo juiz antes do agressor, sendo a mesma presidida apenas por servidores e bacharéis em direito ou juízes, por estes estarem, obviamente, mais capacitados para a prática de tal ato.

Em relação ao rito criminal especial, no procedimento de audiências de instrução e julgamento, o momento para a propositura da transação penal foi deslocado da primeira para a audiência seguinte, para que, nesse ínterim, a mulher vitimada pudesse ser encaminhada a uma equipe multidisciplinar.

Quanto às sanções, cestas básicas e multas foram vedadas como penas a serem aplicadas nos casos de violência dessa natureza, passando a ter vigência em todo o território nacional, o processo, o julgamento e a execução das causas decorrentes da prática de violência doméstica e familiar contra a mulher, podendo seus atos processuais realizarem-se, inclusive, em horário noturno, conforme disposição das normas de organização judiciária. 
Com o advento da Lei Maria da Penha surgiu a necessidade de criação de Juizados Especiais que cuidassem especificamente dos assuntos pertinentes à violência doméstica e familiar, para que os processos ganhassem maior agilidade, além de uma estrutura mais adequada, com investigações mais direcionadas, detalhadas e depoimentos de testemunhas e das vítimas mais complexos.

Recentemente, com a edição da Lei $n^{0} 12.403 / 2011$, entraram em vigor algumas mudanças no CPP no tocante à prisão preventiva onde, de acordo com o novo art. 310 do CPP, ao receber o auto de prisão em flagrante, o juiz deverá: (a) verificar a legalidade da detenção cautelar e, caso contrário, relaxar a prisão ilegal; e (b) verificar se é caso de prisão preventiva. (MARCÃO, 2011, online)

Com a nova redação, a prisão preventiva, segundo o art. 313 do CPP, só é admissível se: (a) a pena máxima cominada abstratamente for superior a 04 anos; (b) o acusado for reincidente em crime doloso com sentença transitada em julgado; ou (c) o crime envolver violência doméstica e familiar, o que a Contrario sensu, fora destas hipóteses, a prisão preventiva é inadmissível. (MALULY; DEMERCIAN, 2011)

\section{Análise do PANORAMA SOCIAL E FiNALIDAdE ATUAL}

No que tange o dispositivo de lei que determina a criação dos Juizados Especiais, infelizmente, este ainda não é cumprido em sua integralidade na maioria dos Estados brasileiros, uma vez que muitos não possuem Juizados Especiais, sendo os crimes de violência doméstica tratados como crimes de menor potencial ofensivo, julgados perante os Juizados Especiais Cíveis e Criminais juntamente com processos de acidente de trânsito e casos de brigas entre vizinhos.

Nesse aspecto, a Lei Maria da Penha mostra-se lacunosa quando apenas sugere a criação dos juizados especiais e não impõe obrigações para a criação dos mesmos. Porém, se observarmos mais amiúde o artigo 33 da mesma lei, notar-se-á que, de forma implícita, a lei goza certa imperatividade em relação à criação dos juizados especiais quando dispõe sobre a competência transitória das varas criminais para que estas possam atuar nas causas a eles pertinentes, facultando ao Estado e à União a regulamentação de sua instalação e funcionamento, de acordo com as necessidades e condições de cada local ou região.

Com a entrada em vigor de referida lei e com as alterações no Código Penal Brasileiro, ocorreram mudanças significativas, senão profundas, vez que, como dito alhures, possibilitou a decretação da prisão em flagrante ou ainda da prisão preventiva aos agressores, mesmo quando as infrações penais cometidas contra a mulher forem consideradas de menor potencial ofensivo. É certo que, para o que o agressor permaneça preso, são imprescindíveis o depoimento e a propositura de queixa-crime pela vítima; do contrário, o mesmo será posto em liberdade devido à impossibilidade da lavratura do flagrante. (NUCCI, 2010)

A pena para agressões domésticas praticadas contra a mulher foi triplicada no Brasil e os meios para a proteção das vítimas cresceram cada vez mais, apesar de ainda insuficientes para atender a demanda, aumentando de um para três anos o tempo máximo de prisão, enquanto a mínima foi reduzida de 6 (seis) meses para 3 (três) meses.

Ressalte-se o papel a ser desempenhado pela Assistência Social nesses casos, que segundo o art. 11 da lei em tela, devem atuar em casos de iminente prática de violência de forma preventiva ou repressiva, respectivamente.

Tal dispositivo é de suma importância, denotando a extrema clareza com que tipifica o papel a ser desempenhado pela autoridade policial, que ganha maior autonomia e poder, aumentando 
de forma significativa sua participação, dever de proteção e cuidado ao tratar do atendimento à mulher vitimada. Tais cuidados são de máxima relevância, pois muitas pesquisas demonstram que o maior medo das mulheres é a vingança do agressor após a formalização da denúncia.

Ressalte-se ainda que a maioria das vítimas, após o oferecimento da denúncia acaba por desistir na persecução processual, em razão do desamparo, pois normalmente não tem para onde ir e acaba voltando para sua residência, sendo alvo de novas agressões, razão pela qual o procedimento criminal é arquivado pelo Ministério Público. Dessa forma, quando são intimadas a comparecerem nas audiências perante o Juizado Especial Criminal, as mesmas acabam por desistir de prosseguir com a denúncia pelo fato das ameaças a que estão submetidas pelo agressor persistirem, uma vez que ainda continuam próximas, convivendo com ele.

Portanto, é de suma importância que a vítima se sinta totalmente protegida para que se consiga prosseguir com o feito, qual seja, denunciar as agressões a que vem sendo submetida e mantê-la segura até o fim do processo.

O papel a ser desempenhado pela autoridade policial e as diversas providências que devem ser tomadas pela mesma a partir do momento em que é registrada a ocorrência do crime, são de extrema relevância, cabendo-lhe o devido encaminhamento da vítima ao Instituto Médico Legal, para que sejam realizados os exames de corpo de delito e demais exames periciais que se fizerem necessários, devendo todos os entes públicos estar apostos para disponibilizarem os serviços especializados para o melhor atendimento desses casos, conforme determinação legal, tornando referidos laudos médicos e demais exames periciais meios de prova a serem admitidos contra os agressores.

A lei subexamine prevê ainda em seu art. 19 a concessão de medidas protetivas de urgência, que poderão ser concedidas pelo Magistrado a requerimento do Ilustre representante do parquet, ou ainda pela própria ofendida, devendo tal pedido ser instruído da melhor forma possível, pela própria autoridade policial ou pela promotoria para melhor embasamento do convencimento do juiz, sendo que tais decisões poderão ser concedidas e, consequentemente, aplicadas uma a uma de forma cumulada, podendo ainda haver a substituição das medidas pleiteadas por outras de maior eficácia sempre que o direito da ofendida ou demais direitos previstos na lei no 11.340/2006, forem ameaçados.

O magistrado poderá ainda, a pedido do Ministério Público e após comprovada a necessidade de novas medidas protetivas ou revisão das medidas já concedidas, ampliar ainda mais o caráter flexível de decisões anteriormente por ele proferidas, determinando a aplicação de novas, ou mesmo, a manutenção em parte das medidas que inicialmente concedeu, alterando apenas algumas características que lhe são inerentes. Valendo salientar mais uma vez que a proteção à mulher vitimada não se restringe apenas a ela, estendendo-se a seus familiares, bem como a todo seu patrimônio. (CUNHA; PINTO, 2008)

O artigo 20 da Lei no 11.340/2006 e seu Parágrafo único, elencam em seu escopo o rol de medidas cabíveis que beneficiam a mulher vítima de violência doméstica.

Outro avanço oriundo da lei, que assegura a proteção à mulher vítima de violência, consiste em sua notificação prévia de todo e qualquer ato relativo ao agressor, bem como a informação de sua entrada, manutenção ou saída da prisão, posto que, antes da lei, a vítima não era informada formalmente de nenhum procedimento que estivesse relacionado ao agressor, participando apenas do processo em dois únicos momentos: em seus depoimentos, perante a autoridade policial e o juiz, deixando assim, de ter sua integridade física preservada, permanecendo em risco.

Atualmente, a vítima passa a ser informada de todos os procedimentos e atos relacionados ao agressor, o que lhe dá respaldo para que ganhe tempo de preparar-se para qualquer 
possível investida contra ela em caso de liberação do mesmo de seu cárcere, trabalhando seu aspecto psicológico para o momento da soltura de seu algoz.

Tais medidas preventivas são também necessárias no momento da decretação da prisão do agressor, que se torna então, cada vez mais violento.

No disposto no parágrafo único do artigo 21, tratado na Lei $\mathrm{n}^{\circ} 11.340 / 2006$, vale ressaltar a proibição da vítima em notificar ou intimar o agressor; trata-se de nova regulamentação, pois antes do surgimento da lei, era praxe que as autoridades incumbissem a ofendida à prática de tal ato, colocando-a em risco de novas agressões. Some-se a isso, o art. 22 do mesmo diploma legal que trata da suspensão ou restrição imediata do porte de arma por decretação do magistrado, com base no Estatuto do Desarmamento, Lei n 10.826/2003, com comunicação aos órgãos competentes, além de seu afastamento imediato do lar, ou local de convivência com a vítima e seus familiares, fixando um limite máximo de distância entre eles, além de determinar a ausência de qualquer contato ou comunicação e a frequentação de determinados locais, a fim de preservar a integridade física e psicológica da mulher vitimada, cabendo, ainda, a determinação sobre a restrição ou suspensão de visitas do agressor aos dependentes menores, através de equipe de auxilio de atendimento multidisciplinar ou através de qualquer outro mecanismo similar, bem como a fixação de alimentos provisionais que, muitas vezes em razão da agressividade e violência de seu desafeto, é proibida de exercer atividade laborativa, limitando-se à condição de dependente.

Já o artigo 23 da Lei contempla a atuação de equipes multidisciplinares no atendimento ou proteção à mulher vitimada, determinando que a ofendida, seus dependentes e familiares sejam devidamente acompanhados nesse processo, bem como da reabilitação dessas pessoas ao seu lar a partir do afastamento do agressor. Cumulado a isso, temos o disposto no Artigo 24, regulando os direitos da vitima afastada de seu lar no tocante à conservação de seus direitos patrimoniais, guarda dos filhos e outros para que não sejam afetados, trazendo tal dispositivo maior segurança.

Portanto, são inquestionáveis as inúmeras transformações que a Lei Maria da Penha trouxe para o ordenamento jurídico brasileiro, principalmente sob o aspecto social, proporcionando uma mudança da visão da sociedade sobre o tema, tornando-a mais ampliada e sensível, com uma maior conscientização das vítimas sobre seus direitos e, o mais importante, a intolerância e o repúdio a qualquer tipo de prática dessa natureza.

Entretanto, devemos salientar que, apesar da boa intenção do legislador quando da criação da Lei e dos benefícios pretendidos quando de sua criação, infelizmente na prática vemos que a ela encontra inúmeras barreiras para sua real aplicação, padecendo e perecendo pela falta de mecanismos estatais para seu desenvolvimento e o real alcance de seu objetivo. Um exemplo disso é a falta de aparelhamento dos Estados para o atendimento das vítimas, como a falta de DDM's e Juizados Especiais, ausência de pessoas qualificadas, de casas de abrigo para o acolhimento e proteção das vítimas etc., causando, com isso, um aumento da violência pela certeza da impunidade, gerada pelo descaso e banalização da lei. O que é muito grave e assustador!

O árduo trabalho exercido pelas DDM's merece ser destacado, pois mesmo funcionando de forma precária e longe da ideal, tem servindo de sustentáculo e apoio à mulheres vitimadas, uma vez que nem todas dispõem de atendimento psicológico, social e jurídico, conforme disposição legal; mas, segundo mapeamento geral feito no ano de 2008, constatou-se que houve um aumento significativo no número de salas, no interior das delegacias da mulher, destinadas à assistência psicológica, social e jurídica. No ano de 2003, apenas $24,5 \%$ das delegacias oferecia serviço de assistência social esse espaço, passando para 30,4\% em 2006. No mesmo ano, 31,9\% tinham espaço para atendimento psicológico, passando para 37,2\% em 2007. Já o atendimento 
jurídico era oferecido por 40,8\% das delegacias em 2003 e diminuiu para 36,0\% em 2006. Redução esta que não significa necessariamente a diminuição da oferta de atendimento, e sim, uma descentralização desses serviços, visto o aumento, nos últimos anos, do atendimento jurídico em núcleos mantidos por faculdades de direito, além da criação de Defensorias Públicas em vários Estados e, em alguns deles, de núcleos especializados no atendimento de mulheres (SENASP, 2007).

Entre os serviços existentes, os principais parceiros, os que mais contribuem para o desempenho das DDM's são aqueles que integram o Sistema de Justiça Criminal - Instituto Médico Legal e outras instâncias da polícia técnica e o Judiciário - e perante o Poder Judiciário, os Juizados Especiais (aplicam a lei $\mathrm{n}^{\circ}$ 9.099/95), Varas Criminais (atendem as ocorrências de crimes sexuais, por exemplo) e, recentemente, Juizados Especiais para a Violência Doméstica e Familiar contra a Mulher, ainda em fase de implantação em muitos Estados. Esses órgãos fazem fluxo do encaminhamento de queixa e do inquérito policial na justiça. A interlocução entre eles e a delegacia da mulher não pode ser avaliada segundo sua existência ou não. Essa articulação entre Delegacias da Mulher, os IML's, o Judiciário (juizados, varas da infância e juventude, varas de família, Ministério Público e Defensorias), serviços de saúde da rede pública e conselhos tutelares foi considerada como ótima ou boa por mais de $60 \%$ das delegacias pesquisadas, (SENASP, 2007).

Na contramão disso, ou seja, nos casos de insatisfação e de péssima articulação, encontramos a insuficiência ou inexistência de casas de abrigo, núcleos, postos de atendimento à mulher, ONG's e conselhos de direitos da mulher também no mesmo percentual, (60\%) sessenta por cento. Vale lembrar que essa articulação não é uma via de mão única, uma vez que tal pesquisa constatou outra grande dificuldade que esses outros serviços possuem na parceria de trabalho com as DDM's, qual seja o isolamento institucional, o desconhecimento sobre a missão institucional de cada serviço, o que acarreta em encaminhamentos equivocados; falta de sensibilização de alguns policiais e a persistência da dificuldade da prestação de informações precisas às mulheres, além do esclarecimento de seus reais direitos, fazendo com que pereginem entre esses serviços, repetindo suas histórias (PASINATO, 2006; CEPIA, 2007).

Conforme dito alhures, apesar dos significativos avanços já registrados, ainda existem inúmeros obstáculos a serem superados, dentre eles a resistência e o preconceito entre os profissionais dos próprios serviços onde os programas são implantados e onde, por vezes, funcionam isoladamente, desprovidos de recursos e materiais disponíveis; o despreparo dos profissionais e a desconfiança em relação a outros serviços, em especial a polícia, são fortes empecilhos para o perfeito funcionamento das DDM' e Juizados, gerando ainda mais nas mulheres que necessitam desses serviços uma insegurança maior no momento da denúncia ou mesmo no prosseguimento dos feitos, pois lhes falta o respaldo para tanto. Todavia, as DDM'S ainda constituem a principal política pública de enfrentamento à violência doméstica praticada contra as mulheres.

\section{4 ÍNDICES ATUALIZADOS SOBRE A VIOLÊNCIA DOMÉSTICA NO BRASIL}

De acordo com seminário promovido pela Comissão de Segurança Pública para debater a violência doméstica, em 2010, mais da metade das mulheres brasileiras já sofreu algum tipo de violência física, psicológica ou sexual - um ato que se repete no País a cada 15 segundos, e mais da metade das mulheres assassinadas no Brasil foram mortas por seus companheiros ou ex-companheiros. Estima-se que 300 milhões de mulheres são agredidas fisicamente por seus maridos ou parceiros no País, anualmente. Segundo dados da Organização Mundial da Saúde (OMS), em diferentes países da América Latina, um número significativo de mulheres afirma ter 
sido vítima de violência pelo parceiro. Em alguns países, esse percentual chegou a 50\%. O menor índice foi de 20\%. (GRIPP, 2011, online)

Dentre os maiores problemas enfrentados pelas mulheres no tocante à violência doméstica é a convivência permanente com o agressor. Não há distanciamento físico, em geral há dependência econômica e não existe tratamento para o agressor, que muitas vezes também foi vítima de violência quando criança, sendo dependente químico ou desempregado.

Somando-se a isso, temos os alarmantes índices de transtornos emocionais desenvolvidos pelas mulheres vítimas de violência direta e indireta, num percentual de $60 \%$ (sessenta por cento), enquanto a porcentagem da população geral tem esse mesmo risco reduzido a $20 \%$ (vinte por cento). Tais ações violentas afetam profundamente a vida psíquica da mulher, sendo, prejudicada em seu conforto psíquico, deixando de ser dona e senhora do seu eu, deixando de governar-se e determinar-se a si mesma, por conta do medo que a paralisa, perdendo, consequentemente, o domínio de seu ser e de sua liberdade.

Diante de todo esse panorama, devemos registrar um dado muito positivo que vem ocorrendo no Estado do Ceará, (um dos Estados Nordestinos detentores de grandes índices de violência contra a mulher) que é o aumento de processos criminais registrados pelo Juizado de Violência Doméstica e Familiar contra a Mulher durante o ano de 2010, cinco anos após a entrada em vigor da Lei Maria da Penha, que totalizou 6.157, o que representa 21\% (vinte e um por cento) se comparado com os 5.059 de 2008, com um crescimento do número de audiências criminais realizadas em 2009, cerca de $110 \%$, passando de 2.624 em 2008, para 5.574 no ano passado. Já a quantidade de sentenças criminais apresentou aumento extraordinário de 435,55\%, uma vez que foram realizadas 4.429 em 2009 contra 827 em 2008, sendo que do total de 6.157 processos de 2009, 3.846 são referentes às medidas protetivas deferidas pelos Juizados.

Desde sua criação, em 2007, o Juizado Especial da Mulher no Ceará já recebeu mais de 10.000 processos, dos quais 6.066 encontram-se arquivados e 6.018 continuam em trâmite. Em janeiro de 2010, a quantidade de processos já havia superado a do mesmo período de 2009. Foram computados 571 processos contra 434 de janeiro de 2009 e 281 de 2008. As medidas protetivas somam 326 contra $282 \mathrm{em} \mathrm{2008.} \mathrm{As} \mathrm{audiências} \mathrm{criminais} \mathrm{totalizaram} 316$ em janeiro deste ano, 2011, contra 148 no ano passado, 2010. Significa dizer que o número de casos tem aumentado, tendo em vista a mudança de postura das mulheres que, tornaram-se mais conscientes de seus direitos, servindo de incentivo para novas denúncias, ou seja, com isso, o medo deu lugar à coragem, onde antes havia receio, hoje existe atitude, pois sabem que existe um mecanismo forte, chamado Lei Maria da Penha, apesar das distorções a serem corrigidas, para protegê-las.

Diante do contexto e dos índices, ora apresentados, não há que se falar ou mesmo cogitar que a Lei venha sendo utilizada como instrumento de vingança, vez que a desigualdade entre os gêneros ainda impera em nossa sociedade em todos os aspectos, apesar de toda a evolução e esclarecimento sobre o assunto. O que se supõe para que tal prática ocorra, é as questões atinentes ao pagamento de alimentos aos filhos, quando o agressor, após a imposição de tais medidas, tenta se esquivar de sua obrigação como forma de punição à vítima, sua ex- companheira, sendo esta a única forma de continuar violentando-a. Ressalvada essa hipótese, é inimaginável tal possibilidade, ante o quadro disposto.

\section{Conclusão}

O advento da Lei Maria da Penha, inquestionavelmente, foi um avanço do ordenamento jurídico brasileiro, que clamava há muito por justiça e pelo fim da impunidade aos atos de extrema crueldade e covardia praticados contra as mulheres. 
É certo que tal diploma padece com a falta da estrutura estatal necessária para seu efetivo cumprimento, mas, graças aos inúmeros movimentos feministas, ao apoio da sociedade e à luta de uma brava mulher cearense chamada Maria da Penha Fernandes Maia, tornou-se efetivamente uma realidade e um poderoso instrumento de coerção e prevenção à prática ou à continuidade de atos de violência de quaisquer gêneros.

Vivemos em uma sociedade que prega o direito à liberdade, à igualdade e, acima de tudo, à justiça, dentre outros. Diante disso, cabe a cada um de nós, enquanto cidadãos, fazermos valer a cada dia nossos direitos e lutar incansavelmente pela sua manutenção, pois somente assim estaremos efetivamente exercendo nossa cidadania, uma vez que o desrespeito gera a intolerância, a injustiça e, por via de consequência, a impunidade.

\section{REFERÊNCIAS}

ALMEIDA, Geilsa Alves. O papel da Delegacia da Mulher no Município de Aracaju no combate à violência doméstica contra a mulher. $152 \mathrm{f}$. Monografia (Pós Graduação em Ciências Sociais). - Universidade Tiradentes, Sergipe, 2010. Disponível em: <http://bdtd.bczm.ufrn.br/ tedesimplificado//tde_arquivos/7/TDE-2010-12-13T105423Z-3160/Publico/GeilsaAA_DISSERT. pdf>. Acesso em: 22.nov.2011.

BRASIL. Lei $\mathrm{n}^{\circ} 11.340$, de 07 de agosto de 2006. Cria mecanismos para coibir a violência doméstica e familiar contra a mulher, nos termos do $\S 8^{\circ}$ do art. 226 da Constituição Federal, da Convenção sobre a Eliminação de Todas as Formas de Discriminação contra as Mulheres e da Convenção Interamericana para Prevenir, Punir e Erradicar a Violência contra a Mulher; dispõe sobre a criação dos Juizados de Violência Doméstica e Familiar contra a Mulher; altera o Código de Processo Penal, o Código Penal e a Lei de Execução Penal; e dá outras providências. Art. $5^{\circ}$ inciso I. Presidência da República. Disponível em: $<$ http://www.planalto.gov.br/ccivil_03/_Ato20042006/2006/Lei nº11340.htm>. Acesso em: 20.nov.2011.

. Lei $\mathrm{n}^{\mathrm{o}} 11.340$, de 07 de agosto de 2006. Cria mecanismos para coibir a violência doméstica e familiar contra a mulher, nos termos do $\S 8^{\circ}$ do art. 226 da Constituição Federal, da Convenção sobre a Eliminação de Todas as Formas de Discriminação contra as Mulheres e da Convenção Interamericana para Prevenir, Punir e Erradicar a Violência contra a Mulher; dispõe sobre a criação dos Juizados de Violência Doméstica e Familiar contra a Mulher; altera o Código de Processo Penal, o Código Penal e a Lei de Execução Penal; e dá outras providências. Art. 11. Presidência da República. Disponível em: <http://www.planalto.gov.br/ccivil_03/_Ato2004-2006/2006/Lei $\mathrm{n}^{\mathrm{o}}$ 11340.htm>. Acesso em: 20.nov.2011.

. Lei $n^{\circ} 11.340$, de 07 de agosto de 2006. Cria mecanismos para coibir a violência doméstica e familiar contra a mulher, nos termos do $\S 8^{\circ}$ do art. 226 da Constituição Federal, da Convenção sobre a Eliminação de Todas as Formas de Discriminação contra as Mulheres e da Convenção Interamericana para Prevenir, Punir e Erradicar a Violência contra a Mulher; dispõe sobre a criação dos Juizados de Violência Doméstica e Familiar contra a Mulher; altera o Código de Processo Penal, o Código Penal e a Lei de Execução Penal; e dá outras providências. Art. 20. Presidência da República. Disponível em: <http://www.planalto.gov.br/ccivil_03/_Ato2004-2006/2006/Lei $\mathrm{n}^{\mathrm{o}}$ 11340.htm>. Acesso em: 20.nov.2011.

. Lei $\mathrm{n}^{\circ} 11.340$, de 07 de agosto de 2006. Cria mecanismos para coibir a violência doméstica e familiar contra a mulher, nos termos do $\S 8^{\circ}$ do art. 226 da Constituição Federal, da Convenção sobre a Eliminação de Todas as Formas de Discriminação contra as Mulheres e da Convenção 
Interamericana para Prevenir, Punir e Erradicar a Violência contra a Mulher; dispõe sobre a criação dos Juizados de Violência Doméstica e Familiar contra a Mulher; altera o Código de Processo Penal, o Código Penal e a Lei de Execução Penal; e dá outras providências. Art. 21. Presidência da República. Disponível em: <http://www.planalto.gov.br/ccivil_03/_Ato2004-2006/2006/Lei $\mathrm{n}^{\mathrm{o}}$ 11340.htm>. Acesso em: 20.nov.2011.

. Lei $\mathrm{n}^{\mathrm{o}} 11.340$, de 07 de agosto de 2006. Cria mecanismos para coibir a violência doméstica e familiar contra a mulher, nos termos do $\S 8^{\circ}$ do art. 226 da Constituição Federal, da Convenção sobre a Eliminação de Todas as Formas de Discriminação contra as Mulheres e da Convenção Interamericana para Prevenir, Punir e Erradicar a Violência contra a Mulher; dispõe sobre a criação dos Juizados de Violência Doméstica e Familiar contra a Mulher; altera o Código de Processo Penal, o Código Penal e a Lei de Execução Penal; e dá outras providências. Art. 24. Presidência da República. Disponível em: <http://www.planalto.gov.br/ccivil_03/_Ato2004-2006/2006/Lei $\mathrm{n}^{\mathrm{o}}$ 11340.htm>. Acesso em: 20.nov.2011.

CUNHA, Rogério Sanches; PINTO, Ronaldo Batista. Violência Doméstica. São Paulo: Revista dos Tribunais, 2007.

Violência doméstica: Lei Maria da Penha (Lei n ${ }^{\circ}$ 11340/2006), comentada artigo por artigo. 2 ed. rev., atual. e ampl. São Paulo: Revista dos Tribunais. 2008,

DIAS, Maria Berenice. A lei Maria da Penha: A efetividade da Lei n ${ }^{\circ}$ 11.340/2006 de combate à violência doméstica e familiar contra a mulher. São Paulo: Revista dos Tribunais, 2008.

DOXSEY, Sônia Maria Rabello. Violência familiar: Cidadania precária nas famílias. Comissão científica do IBDFAM, no III Congresso de Direitos de Família, Ouro Preto, 2001.

ELUF, Luíza Nagib. Dos crimes contra os costumes e assédio sexual. São Paulo: Jurídica Brasileira, 1999.

GRIPP, Patrícia; OLIVEIRA, Rejane. Violência doméstica se repete a cada 15 segundos. Direito2. com. Disponível em: <http://direito2.com/acam/2003/nov/11/violencia-domestica-se-repete-acada-15-segundos_1>. Acesso em: 22.nov.2011.

HERMANN. Leda Maria. Maria da Penha, lei com nome de mulher: Violência Doméstica e Familiar. Campinas: Servanda, 2007.

MALULY, Jorge Assaf; DEMERCIAN, Pedro Henrique. A prisão preventiva e as suas hipóteses previstas no art. 313 do CPP, conforme a lei $n^{0}$ 12.403, de 2011. Associação Paulista do Ministério Público. São Paulo, 2011. Disponível em: <http://www.midia.apmp.com.br/arquivos/ pdf/artigos/2011_prisao_preventiva2.pdf>.Acesso em: 23.nov.2011.

MARCÃO, Renato. Lei n ${ }^{\circ}$ 12. 403: o art. 310 do CPP e a inafiançabilidade na visão do STF. JUS NAGIVANDI. Teresina: ano 16, n. 2953, 2011. Disponível em: < http://jus.com.br/revista/ texto/19676/lei-no-12-403-11-o-art-310-do-cpp-e-a-inafiancabilidade-na-visao-do-stf $>$. Acesso em: 22.nov.2011.

MORRISON, Andrew R.; BLEHL, Maria Loreto. A Família Ameaçada: Violência doméstica nas Américas. São Paulo: Fundação Getúlio Vargas e Banco Interamericano, 2000.

NUCCI, Guilherme de Souza. Manual de direito Penal: Parte Geral. Parte Especial. 6 ed. rev., atual. e ampl. São Paulo: Editora Revista dos Tribunais, 2010. 
UNBEAUM, Sandra. Reunião sobre comunicação e violência contra as mulheres: relatório. Instituto Patrícia Galvão. São Paulo, 2005. Disponível em: <http://www.patriciagalvao.org.br/ Relatorio_comunicacao_violencia.pdf>. Acesso em: 24.nov.2011.

\section{UPDATED VISION OF DOMESTIC VIOLENCE IN BRAZILAND} THE TRUE EXTENT OF THE MARIA DA PENHA LAW - LAW N. 11.340/2006

Abstract: This article focuses the development and recognition of the rights of women victims of domestic violence in Brazil. It is intended to address the important issues, ranging from the origin of the first feminist movements in our country to the support centers and special courts created specifically to protect women in need of legal support.

Keywords: Domestic violence. Maria da Penha Law. 